\title{
Environmental Engineering, Water
}

National Cancer Institute

\section{Source}

National Cancer Institute. Environmental Engineering, Water. NCI Thesaurus. Code C18765.

Environmental eng ineering focusing on issues related to water quality management and remediation. 